\title{
Training and Development
}

Sue DeWine

President Emerita, Hanover College

dewine@hanover.edu

Mary M Eicholtz

Assistant Professor, Kutztown University of Pennsylvania

eicholtz@,kutztown.edu

Kim White-Mills

Associate Professor, IUPUI

kwhitemi@,iupui.edu

Word count (not including abstract): 6400

\begin{abstract}
:
Training and Development are processes that lead to change in individual organizational members for the primary benefit of the organization. These processes are distinct from consulting, which helps decision makers arrive at those same goals. Training and development as well as consulting are functions for communication specialists. In this entry, the major dimensions are described. Needs assessment, technology and training, approaches to training, evaluation of training programs, and adult learning and professional development are addressed. Training as a career in organizational communication is described.
\end{abstract}

Training and development are two rather broad terms that cover educational programs that occur in all types of organizational environments from health care to manufacturing. The term development in this context usually refers to the professional skills a worker has or acquires during the course of a career. It is the broadest term under which education and then training would be included. A training program is intended to improve an individual's professional abilities and skills. The content could be focused on general communication styles, the psychology of work, or job skills to do a particular task. What all types of training have in common is that training programs are designed to improve the productivity and effectiveness of organizational members for the benefit of the organization.

Communication specialists either are developing the actual content when the focus is on improving communication in the organization or are developing the training format for specific job related skill training. In either case, the communication specialist delivers content designed to improve communication among organizational members or provides communication activities that help deliver job skills more effectively. An example of training focused specifically on a communication problem could be a case of misunderstanding. A training session on interpretation of messages, and ways to check your understanding of someone else's message,

This is the author's manuscript of the article published in final edited form as:

Dewine, S., Eicholtz, M. M., \& White-Mills, K. (2017). Training and Development. In The International Encyclopedia of Organizational Communication (pp. 1-14). American Cancer Society. https://doi.org/10.1002/9781118955567.wbieoc207 
could include a role-play where the sender and receiver of the message reverse roles and present their interpretation of the message sent.

Trainers use a variety of techniques to deliver training including: brief lectures, role-play, reenactments, guided self-discovery, self-analysis instruments, and observation of one's communication in practice. All approaches are designed to provide useful feedback to the participant on their most effective and ineffective personal communication style.

\section{History}

The first trainers in industry were efficiency experts whose goals were to identify methods to improve employees' speed and efficiency. Time and motion studies at the turn of the $20^{\text {th }}$ century studied the actions of workers on assembly lines to determine how their movements could be changed to speed up the line. The Hawthorne studies conducted from 1924-1932 at the Hawthorne Works of the Western Electric Company in Chicago discovered that worker attitudes had an impact on performance. These studies changed environment parameters like lighting and heating to determine if their performance improved or worsened. The astonishing discovery was that performance improved no matter what changed in the environment. The conclusion was that workers responded to the perception that management was showing them some attention and actually cared about their environment and performance. Therefore, no matter what management did, even when they implemented what were considered harsher conditions, workers responded positively to the attention paid to them. This was the beginning of the field of management training and development (Modaff, Modaff, \& DeWine, 2012).

One of the first communication scholars to write about training and consulting was Charles Redding, a professor at Purdue University. Redding advocated for professional standards for academics who wanted to work in the private sector and provide communication training to employees (Redding, 1984). In the forward to The Consultant's Craft, Redding wrote "In every instance of organizational malaise that comes to mind, at some time and in some way, human communication behavior has been significantly involved. Indeed, there are those scholars who have persuasively made the case that a communication failure is at least one of the basic sources underlying every organizational failure" (DeWine, 2001, p. xxxiii). Thus began the focus on using communication theories and strategies for improving communication in organizations. Redding was a pioneer of organizational communication and the first to provide strong advocacy for using communication research to improve communication in organizations in addition to studying it.

Edger Schein was another early organizational development specialist who identified three classic approaches to training and consulting: Purchase, Doctor-patient, and Process. With the Purchase model, the client identifies the need and hires someone to deliver it. In the Doctorpatient model, the client asks for help to diagnose and fix the problem. In the Process model, the consultant or trainer joins the management team in determining what course of action would be most effective. These models have faded as more theoretical approaches to training and consulting have taken hold. For example, Waldeck and Seibold (in press) advocate for a scholarly approach to training and development. Twenty scholar/practitioners have contributed to this edited book, each sharing their unique approaches to training and consulting in organizations. These authors conceptualize training and consulting as more relational activities involving both organizational members and other stakeholders, where theory and practice are viewed as reciprocal and mutually enriching. 
In the following pages the major dimensions of training will be identified by: defining professional and organizational development and comparing it to consulting; examining trainee needs assessment, which must come before designing any training program; describing effective training approaches and the adult learner; exploring the use of technology in training, and describing the evaluation of training programs.

\section{Key Concepts}

Training and development are both processes that help an organization and its members navigate change. Training is the most specific process and closes the gap between an employee's current skill and knowledge level and the levels needed for the organization to move forward. Training leads to individual professional development. An organization uses training to meet their organizational development goals. These goals include making the organization more effective, especially during change (Chung-Judge \& Holbeche, 2011).

Training and consulting are both part of the helping professions. Training is the direct delivery of skills to enhance human performance. These skills can be technical knowledge or relationship skills. Consulting is intervening into a system to stop some destructive human process and/or improve the ability of the work group or total organization to function.

In the Consultant's Craft (DeWine, 2001) training is defined as the direct delivery of skills, through some formal process, to enhance human performance. These skills can be technical knowledge applied to the organization's product or service, or relationship skills applied to working with and directing the work of others. Destructive processes may be affecting the organization's ability to produce quality products, provide services, or function without high turnover and disputes. Training helps change negative cycles and can be delivered by internal employees or external trainers/consultants.

Beebe, Mottet, and Roach (2013) use a model to compare development, education, and training: "Development is any behavior, strategy, design, restructuring, skill or skill set, strategic plan, or motivational effort that is designed to produce growth or change over time" (p. 12). Development is the largest umbrella, then education, and then training. Development is often used in conjunction with training. There are two types of development; organizational development and professional development. Both are important to training outcomes. At the organizational level, the outcome of development might include making more money or creating a new product. At the individual level, development would include improving one's skills or knowledge to accomplish organizational and personal goals. Regardless, training is a means to development at both the organizational and professional levels. A needs assessment helps determine exactly what kind of development would be most helpful. This is the first step in the training process.

\section{Needs Assessment}

Before conducting training, providing professional development for employees and moving an organization to a new place through organizational development, a needs assessment must be conducted to determine the most effective training approach for the trainees and the situation. . It articulates the difference between where the organization's performance is and where it needs to be. A needs assessment defines the issues facing the organization and its members and provides a plan for moving the organization forward. The needs assessment happens in two steps. The first step focuses on the organization by analyzing the barriers for growth and progress. The second 
determines the specifics for what a training session will include and how the session will be conducted.

There are several reasons for conducting an organizational needs assessment. The first reason is to determine whether training is needed. Not all problems are the result of poor employee performance. Management decisions or miscommunication can result in issues that cannot be corrected through training. If employee performance is the issue, a needs assessment can determine the causes of poor performance from both a skills and knowledge perspective. A needs assessment can also help determine the content and scope of training necessary to produce the desired outcomes for the organization and what those outcomes should be. It will also provide a basis of measurement for determining success. Finally, an assessment provides management with the necessary data to support training that needs to be conducted (Lawson, 2013).

Before the needs assessment process can begin, the trainer or consultant must identify who can provide the information necessary for the assessment or who needs to be assessed. One group of individuals is the senior management. Information from this group can provide valuable information about the direction of the organization, performance of employees, and external challenges. Additionally, their support is necessary in the event the assessment identifies a problem that training can correct.

The assessment might also focus on the target population with the organization. Training might be most helpful for these individuals. Data might also be collected from the target group's managers or the individuals who report to them. Sometimes information from human resources, vendors, clients, customers, industry experts and even competitors might be helpful in defining who needs training and the content of that training.

The needs assessment process contains five steps. The first step is to define the problem. Understanding the organizational context through its mission statement and goals as well as discussing the focus of the organization with upper management is the place to begin the conversation. The desired outcome minus the current outcome equals the need. This gap identifies where training should happen and helps set objectives. Once the objectives have been set, step two involves deciding on the assessment design. The method for collecting data can depend on a variety of factors including time, cost, and support from management. A trainer or consultant wants to be as thorough as possible without being intrusive. Many organizations do not want to invest in the assessment process, but rather move right into the training, or what they believe is the solution stage. Methods of needs assessments have both advantages and disadvantages and these should be weighed in making the decision of which type of needs assessment to conduct. After developing an assessment plan, data can be collected in step three.

Like other types of research, the methodology selected yields different results. These methods include both quantitative and qualitative data. When time is a constraint, interviews might be used to gather detailed information with only a few individuals. However, the results can be invaluable in understanding the context of the issues. Group interviews or focus groups are also utilized. With this method, the interaction among participants as well as the more efficient use of time can be beneficial. Questionnaires or surveys, either electronic or paper, help understand an individual's perspective on the issue and in identifying where trainees need additional knowledge and skills. A trainer or consultant might also review organizational documents or observe people completing a task or solving a problem to identify a need. Step four involves analyzing the data from an objective stance to get a clear understanding of the issues and gaps that exist. Once the data is analyzed, solutions and recommendations can be made. The 
final step is providing the feedback to those in decision making positions, which includes both the results of assessment and the recommendations for future action. This feedback can take the form of a written report or an oral presentation or both. The trainer must help decision makers take the next step (Lawson, 2013).

If the next step is to provide training to organizational members, trainers or consultants must continue the assessment process by identifying specifically what will be covered in the training program and how best to conduct the training. The same process will occur but this time with the potential trainees. The need is the gap between the desired employee performance and the current level of performance. This gap is what needs to be covered in the training. Gathering these data can be done in several ways. Pre-training questionnaires can be distributed and collected for analysis. The trainer can do direct observation prior to the training, and supervisors or direct reports can be contacted for interviews. However, there is not always the time or support for this type of intervention. Often on-the-spot assessment may need to be implemented as the first activity of the training session. A variety of activities or discussions can be used to assess quickly what participants know and how they would benefit from the training. The trainer may need to adjust their training presentation to meet these needs.

In the past, trainers were restricted by time and resources in their ability to conduct needs assessments. As more online opportunities became available to connect with potential training participants, as well as access to many layers of the organizational hierarchy, assessment has become less time consuming. In addition to easier and timelier data collection, online software also allows for more efficient data analysis. These electronic resources allow the ability to make informed decisions in defining the problem and recommending training solutions to the organization.

\section{Understanding the Adult Learner}

There is a distinct difference between teaching and training. Teaching, or the pedagogical model, is what most learners have experienced in school and how early training programs were conducted It is the standard most people imagine when walking into a training session. It is also what participants are comfortable experiencing. The pedagogical model makes several assumptions about learners. These assumptions include the premise that the teacher is responsible for the content and process of what will be learned and that the learner is passive. This assumption puts the teacher in the role of expert and sets up the expectation that the teacher will impart his or her knowledge to the group. The model also purports that the learner is there because they have to be. Learning is information-centered and motivation for the participants is external. The teacher controls the learning.

However, most adult learners prefer an andralogical model developed by Malcom Knowles (1990). From this perspective, the learner is self-directed and is involved in the planning, implementing, and evaluation of their learning. The trainer creates the environment and facilitates the process in partnership with the learner. Additionally, this perspective recognizes that the adult learner wants to bring their experiences to the training session. They want their knowledge and contributions recognized in the process. Adult learners also need to believe there is a need to learn something new. Practicality is the most important reason to learn something new. They prefer to look at training as being problem-centered, rather than subjectcentered. Adult learners also prefer real-world examples and applications so they can improve their working situations and solve problems more effectively. All aspects of the training from ice-breakers to activities to discussions need to be relevant. Finally, the andralogical model 
recognizes that motivation to learn is internal. When the adult learner is a participant the training process contributes to their self-esteem, increases their self-confidence or improves their position in the organization.

The process of training is also different from teaching for the adult learner. Although they might recognize theory as interesting, adult learners prefer concrete applications (Beebe et al., 2013). They also require different types of training techniques. Because the trainer's responsibility is to facilitate the learning process rather than simply providing information, several techniques that cover the same material may be necessary to for the learner to retain the information. Adult learners learn better in informal and comfortable training environments. They prefer interacting with both the trainer and their fellow participants. Room set-up and the ability to move around take the focus away from the trainer and allow the trainee to seek knowledge in many areas. Finally, adult learners prefer hands-on activities and enjoy learning by doing. The andralogical model reflects the best practices of good training.

Adult learners process information in a variety of ways and with varying efficiencies. Not everyone processes information the same way. Trainers need to be aware of the six perceptual modalities (James \& Galbraith, 1985) and incorporate them into the training program and activities. When learners receive information through more than one perceptual modality, they are more likely to retain the information. The first modality is visual. Information the trainees read or observe would be included in this format. Watching a video, looking at a diagram or map, or other computer generated visuals, would be part of this modality. Print is the second perceptual modality and is similar to visual; however, this modality is specific to text such as instruction sheets, case studies, or handouts. The third modality is aural, or sound. Learners process information from listening to the trainer or other participants, music, a recorded call with a customer, or other noises relevant to the training, like how an engine sounds. Learners also learn through interacting with others, which is the fourth modality. Discussion groups, team building exercises and ice breakers all take advantage of this modality. Some learners prefer to process information through the tactile modality. Making the dish in a cooking class or putting together a puzzle in a learning activity uses this modality in the learning process. Finally, the perceptual modality of kinesthetic identifies that individuals need to move around to make sense of the information. Role plays and simulations are examples of processing information through this perceptual modality and help trainees understand the concepts being presented. Understanding how adults learn can enhance a trainer's effectiveness.

\section{Training Approaches and the Adult Learner}

Approaches to training are directly affected by the audience receiving the training. As mentioned above the adult learner comes with special needs and expectations. Therefore, some training approaches are more effective than others.

Two journals are of special interest to the examination of training approaches. One was published by the American Society for Training and Development titled Training and Development Journal (later retitled Training and Development, and Training \& Development, published from 1966 until July 2014). This journal covered practical issues faced by professionals in the field of training. It was written more for the practitioner than the researcher. The second is a relatively new publication, starting in 2007, the International Journal of Strategic Communication and is published by Taylor and Francis. This journal is more management focused but certainly covers a wide range of topics faced by trainers from a more philosophical or theoretical point of view. 
In both of these journals, and in many other publications examining approaches to training, the authors identify case studies as one of the most effective ways of approaching training. Case studies are narratives or short stories about an organizational issue. The case study method was originally developed by the Harvard University Business School, which has used the case study method as the basis for their management training for decades. Harvard's version involves detailed histories, financial forecasting, and marketing projections. A training consultant who wants to focus on communication strategies or styles can use more simple but elegant case studies based on true to life examples and models. This narrative or short story about some organizational issue allows participants to analyze what they might do differently if they were in the same situation. Cases should be selected or developed for a training session based on issues the group is facing. There is seldom a right or wrong answer but multiple ways to respond to the issues raised in a case. The training participants bring their own experiences and perceptions to the case. It is those personal perceptions that become the focus of the learning experience.

For adult learners, case studies often provide a reality with which they are familiar. Good case studies provide enough details for the participants to appreciate the complexity of any situation. Keyton (2003) and DeWine and Eicholtz (2000) provide some examples of case studies and their use. The last portion of the edited book by Waldeck and Seibold (in press) provides case studies to demonstrate the use of communication theories and strategies to approach some organizational problem.

Team development is another approach to training that is as much a staple as the case study. Currently scholars, as well as practitioners, use the work group to help organizational members identify communication patterns that are helping a group move forward with decision making. A focus on strengthening the interactions among team members is probably one of the most critical to organizational success. Even simulated small groups foster interpersonal relationships among group members. Members begin to feel more comfortable with each other, which makes consensus easier to achieve. Structured experiences are exercises intended to allow individuals to try out behaviors in a relatively safe environment. These experiences are designed to engage participants in the learning process. The trainer leads the participants in an activity that is structured in such a way as to help participants learn communication skills needed on the job. They are carefully developed and lead to discussions about applications to the work world.

The trainer can develop his/her own structured experience or use ones already developed by training professionals. The Annual Handbook for Group Facilitators: Training and Consulting published by Jossey-Bass/Pfeiffer, 1973-2000 has one of the best collections of structured activities. One classic example of a structured exercise is the broken square. The point of the activity is to demonstrate that in order for the group as a whole to succeed individuals sometimes must give up their personal goals. It is a hard lesson to learn in real life but this activity is a nonthreatening way to bring home the point (see DeWine, 2001, p. 299). Most importantly, the trainer or consultant should follow any simulated or structured experience with a debriefing. Led by the trainer or consultant, a debriefing allows participants to describe simply what happened, how they reacted, and then move to an analysis of what participants learned from the experience. Finally, the debriefing ends as trainees explain how they would apply this knowledge to their work experiences. A facilitator should spend approximately twice as much time discussing the activity as was spent participating in the activity. Sometimes the trainer will use this stage to help participants make commitments to what they will do with what they have learned. 
Role play is another training approach that provides participants with an opportunity to understand an issue from a different perspective. Participants act out the issue or problem. This can be done by individuals or by groups. The trainer can ask that participants reverse roles from their normal position, serve as an alter ego for someone playing a role and provide advice about how to respond in the situation, or use a fish bowl where participants observe two or more people role play a particular scene. Role plays should be voluntary, as the trainer should never force a normally shy person into a position of having to act in front of an audience. However, the discussion that follows can be as useful to the non-participant as to those who have acted the scene. Role plays and structured experiences can be more intense than case studies or typical discussions yet all have the potential to raise significant personal reactions to challenges individuals face at work. The facilitator must be prepared to allow participants to explore their own reactions to these experiences while keeping the discussion among group members focused on training themes. Conflict is often caused by miscues in the communication process. A specific example of using training to help resolve conflict would be using a role play and asking individuals in the communication process to role play the opposite point of view to their personal belief.

Structured activities, role plays, simulations and self-analysis instruments are all useful tools. Whatever tools the trainer uses, the most important factor is what the participants learn about their own behavior at work and how their behaviors might be helping or hindering their individual or the progress of the group. For a sampling of different training techniques, see DeWine (2001) and Lawson (2009).

Another approach to training is to engage the participants in planning the training itself. During the needs assessment process participants may identify techniques that will help them address the issues they are facing. Especially with adult learners, using them as resources makes them central to the process.

Regardless of the training approach, a commitment to collaborative learning requires the trainer and communication specialist to encourage participant interaction through enhanced interpersonal communication. By learning from each other, trainees are more vested in and accepting of the information being presented and are more likely to transfer the information to their workplaces. This assurance can lead to better results from the training.

\section{Technology and Training}

New technologies have emerged that significantly affect the training endeavor for both training professionals and learners (Stephens \& Mottet, 2008). Today, trainers have access to multiple technologies including virtual learning communities, interactive video, computer simulations, and web-based learning tools, to name a few. These technologies are being used in a myriad of communication training situations, from medical education to teacher and graduate student training to the military and the airline industry. Communication professionals are using technology to deliver training for organizational members in communication content areas including presentation skills, team building, interviewing, and listening. Advances in technology are making it easier and more affordable to bring training programs to learners, and to wider audiences of learners. Today, training professionals must not only be facile in using each of these new technologies, but also be equipped to evaluate the implications for learning and adaption for the learners.

Virtual learning communities have been used in training since the late 1990s. Often used to augment face-to-face training sessions, they can also be used after the training sessions have 
concluded to reinforce concepts learned earlier. In one virtual learning community, trainees can access a resource center, a management forum, searchable case studies, and a message board for posting and viewing answers from other trainees.

Online and web-based technologies have emerged as one of the most often used mediums. Online and web-based technologies allow professionals to administer training while in face-to-face settings as well as in self-administered, asynchronous settings. In such settings, users are directed to interactive. The learner is able to access the materials from a remote location other than the organization, navigate through the training materials at a self-directed or timed pace, and engage in objective assessment throughout the training. Online and web-based training technologies require a sophisticated level of technical expertise and knowledge for the trainer.

Computer-based, interactive user-experienced based training using simulation and virtual reality are also widely used in today's training environments. These simulations are typically programs that include a model of a system or a process. Users are directed through various scenarios in which the training content is applied. The simulations are focused on aiding the trainee in developing complex cognitive skills. Much of the training using simulation and virtual reality technology aligns with social cognitive theory. This model assumes that the simulation is engaging, motivating, and offers practice, which will in turn lead to positive self-efficacy (Castellano, 2015). Improved performance is typically the desired outcome of training from the learner's, the trainer's, and the organization's perspective.

Organizational professionals investigate the value of such technologies as a part of training evaluation research. Much of the research addresses issues such as ease of use, content and organization, transferability of training, and general effectiveness of online and web-based training, and other interactive training technology. To be most effective, learners need to find the technology accessible and engaging while organizations want to know that learners are developing the required competencies. Communication training professionals must address issues of pedagogy, integration into the training situation, learner needs, usability of the technology, lower costs of training, and effectiveness of training using technology.

With the influx of social media into our social lives, there are also greater expectations for the use of social media as a way to conduct training in the future. Mobile learning, crowdsourcing, and social networks are other forms of technology expected to become regularly used tools by training professionals. Such advances in technology have enriched the training professionals' potential for implementing optimal learning outcomes and for maximizing the benefits of training.

\section{Evaluation and Training}

Over the past two decades, more communication training programs have been conducted than ever before. Communication professionals and human resource professionals who design and implement these programs are also responsible for conducting evaluations of training. Too frequently, however, training evaluation (i.e., the use of systematic evaluation procedures or evaluation research) is not used to assess these programs. Although a great many organizational communication professionals have endorsed formal evaluation of training programs, evaluation of training and the impact of training programs are not always supported by organizational leadership, and thus training evaluation is not always conducted. A general conclusion about training evaluation, drawn from many human resources professionals has been that while information about learners' attitudes regarding the training programs are collected, there is not 
always organizational support to measure other important issues such as changes in cognitive, affective, or performance outcomes. Training professionals may not be allowed to design experimental or pre-test, post-test evaluation designs, or post-tests of the economic or financial benefit of training to the organization. Obstacles to evaluation and the use of inadequate training evaluation methods contribute to the ongoing problems with training evaluation.

Organizational leaders have been surveyed in an attempt to understand why there is a lack of extensive evaluation of the effectiveness of training programs. DeWine (2001) reported that organizational leaders cite numerous obstructions to training evaluations. Some organizational leaders believe that there is simply no way to measure the impact of the training, and thus are not supportive of providing funding for training evaluation. Some leaders are simply not aware of what information should be collected to provide them with useful evaluation information. Additionally, many organizational leaders have reported that there is no feasible way to translate the impact of training into financial gain for the organization. Finally, some organizational leaders report that evaluation is not necessary since there is no accountability for training outcomes or results. Communication professionals, trainers, and organizational management share the burden of developing and implementing appropriate standards and criteria for training and development programs, and for overcoming the obstacles to effective training evaluation methods.

When evaluation is conducted, it is sometimes done using less than adequate methods. Far too often, the impact of training is measured only in terms of learner satisfaction or opinionbased evaluation. Further, baseline data is often absent or not collected before the start of training programs, making it impossible to evaluate changes in knowledge or ability based on the training intervention. Even as late as 2005, the most common methods for collecting evaluation information were based on informal comments and attendance records. However, since that time more communication training and development professionals have begun to conduct systematic evaluations of training programs, and report results of systematic research studies about the value of training evaluation methods (Edgar \& Hyde, 2005).

Some of the most often used, and appropriate methods of training evaluation include measures of affective or cognitive behavior from pen and paper tests, survey questionnaires, or assessments of job performance. Pen and paper tests (or electronically-delivered tests) are typically administered to the trainees in the training environment, which aim to measure their progress in terms of conceptual learning because of the training. Survey questionnaires are often administered to the learners to assess attitude change regarding a variety of issues related to the organization and the training. Survey questionnaires can be especially beneficial if given before and after the training. Onsite observations of job performance or observations of job simulations are sometimes made by the trainers and managers to evaluate the degree of job performance because of the training.

One of the most effective ways to evaluate the impact of training is to design and administer evaluation materials during the needs assessment stage of the training program. An appropriate and effective pre-test, post-test design can provide the professional and the organization with meaningful information regarding transfer of knowledge and practical application skills gained from training. Finally, the most recent and most comprehensive instrument developed specifically to assess the impact of training on behavior changes and job performance in more detail is the Training Impact Questionnaire (TIQ) (DeWine, 2001). The questionnaire is designed to answer the question of how much trainee change, as a function of the training, subsequently affected job performance. 
DeWine (2001) suggests that Kirkpatrick's four levels of training evaluation continue to serve as the model for evaluating training. The first level of training evaluation, reaction, is the most common level of evaluation. The reaction level involves measuring training participants' initial and general level of satisfaction with the training; often measured through the "happygram." A second level of evaluation, knowledge, goes beyond measuring satisfaction of the trainees to assess the learning of the trainees; knowledge is often measured through objective tests. The third level of evaluation, behavior is concerned with competence or skill development, as measured through the TIQ. A final level of evaluation in Kirkpatrick's model is organizational outcomes. As implied, a measure of effectiveness of the training on the organizational outcomes for the trainees is the focus. Examples of desired organizational outcomes include drops in the turnover rates or increases in advancements.

If training and the impact of training is to be effectively and meaningfully evaluated, organizational professionals must be both able (financially supported by the organization) and willing (proficient and confident) to utilize the appropriate evaluation methods and evaluate at the highest levels of evaluation. Finally, advances in technology have not only positively affected the training situation, but have also served as a stimulus for more systematic evaluations of training programs. Technologies are making it more feasible to conduct training evaluation, and communication professionals appear to be at the forefront of utilizing technologies to conduct more appropriate and more frequent training evaluations.

\section{Future Directions}

Training and development must necessarily be influenced by technology. Technology dramatically changes the way in which training is delivered. These changes are outlined in the previous section on "Technology and Training" with a focus on social media and mobile learning. The examples cited point to ways in which training will be shaped in the future.

At the same time, face-to-face training and learning will always be necessary to help individuals practice the skills needed for successful communication. Because of social media and the lack of presence with another person, there will be an even greater need for traditional training and development.

SEE ALSO:

IEOC0016

IEOC0018

IEOC0019

IEOC0020

IEOC0031

IEOC0034

IEOC0039

IEOC0047

IEOC0050

IEOC0097

IEOC0162

IEOC0188

IEOC0194 


\section{References}

Beebe, S. A., Mottet, T. P., \& Roach, K. D. (2013) Training and development: Communicating for success $\left(2^{\text {nd }}\right.$ ed.). New York, NY: Pearson.

Castellano, S. (2015). Innovations in learning technology. TD: Talent Development, 69(3), 6466.

Chung-Judge, M, \& Holbeche, L. (2011). Organizational development: A practitioner's guide for $O D$ and HR. London, England: Kogan Page.

DeWine, S. (2001). The consultant's craft ( $2^{\text {nd }}$ ed.). New York, NY: Bedford/St. Martin's.

DeWine, S., \& Eicholtz, M. (2000). Managing after the merger: Feedback at BAS case analysis. Management Communication Quarterly, 13, 679-684. doi:10.1177/0893318900134006

Edgar, T., \& Hyde, J. N. (2005). An alumni-based evaluation of graduate training health communication: Results of a survey on careers, salaries, competencies, and emerging trends. Journal of Health Communication, 10, 5-25. doi:10.1080/10810730590904553

James, W. B., \& Galbraith, M. W. (1985, January). Perceptual learning styles: Implications and techniques for the practitioner. Lifelong Learning, pp 20-23.

Keyton, J. (2003). Teaching a pig to sing? Management Communication Quarterly, 16, 453-458. doi:10.1177/0893318902238901

Knowles, M. (1990). The adult learner: A neglected species ( $4^{\text {th }}$ ed.). Houston, TX: Gulf.

Lawson, K. (2009). The trainer's handbook. San Francisco, CA: Wiley.

Modaff, D. P., Modaff, J. A., \& DeWine, S. (2012). Organizational communication: Foundations, challenges, and misunderstandings. New York, NY: Allyn \& Bacon.

Redding, W. C. (1984, November) Professionalism in training: Guidelines for a code of ethics. Paper presented at Speech Communication Association, Chicago, Il.

Stephens, K., \& Mottet, T. (2008). Interactivity in a web conference training context: Effects on trainers and trainees. Communication Education, 57, 88-104. doi:10.1080/03634520701573284

\section{Further Reading}

Bantz, C., DeWine, S., \& Shockley-Zalabak, P. (2005). Practicing what we preach: Communication theories in higher education administration. Management Communication Quarterly, 18, 407-431. doi:10.1177/0893318904270938

Beebe, S. A., Mottet, T. P., \& Roach, K. D. (2013) Training and development: Communicating for success $\left(2^{\text {nd }}\right.$ ed.). New York, NY: Pearson.

Craig, R. L (Ed.) (1996). Training and development handbook: A guide to human resource development ( $4^{\text {th }}$ ed.). New York, NY: McGraw-Hill.

Kearney, P. (2008). Special issue: Instructional communication in organizational contexts: Innovations in training and consulting. Communication Education, 57, 415-416. doi: $10.1080 / 03634520802324116$

Shockley-Zalabak, P., Morreale, S., \& Hackman, M. (2010). Building the high-trust organization: Strategies for supporting five key dimensions of trust. San Francisco, CA: Jossey-Bass.

Waldeck, J., \& Seibold, D. R. (Eds.) (in press). Consulting that matters: A handbook for scholars and practitioners. New York, NY: Peter Lang. 


\section{Brief Biographies}

Sue DeWine, $\mathrm{PhD}$, Hanover, IN, USA, is a researcher and practitioner in training and consulting with applied communication as her major research area. After serving as a professor and consultant to corporations, education, and government organizations for 30 years, DeWine became Provost of Marietta College and served for seven years, and President of Hanover College for eight years retiring in 2015. The Consultant's Craft: Improving Organizational Communication was her most significant and impactful work.

Mary M Eicholtz, PhD is Assistant Professor at Kutztown University of Pennsylvania, USA. Her research areas of interest include organizational culture and identification, learning assessment, and leadership. Some of her publications include a chapter on Organizational Communication in Keith Massie (Ed.) Communication connections: From Aristotle to the internet (2 ${ }^{\text {nd }}$ ed.) Kendall Hunt: Dubuque, IA. Her research has been published in Journal of Communication Administration and Management Communication Quarterly.

Kim White-Mills, PhD is Associate Professor at Indiana University Purdue University, Indianapolis, USA. Her research areas of interest include organizational leadership communication and change, curriculum development, and assessment. Her work has been published in journals including Management Communication Quarterly, The Journal of Business Communication and the Journal of Communication Administration.

Key words: Business and management, Case studies, Consulting, Communication skills, Corporate communication, Employee performance, Employee knowledge, Needs assessment, Strategic communication, Technology 